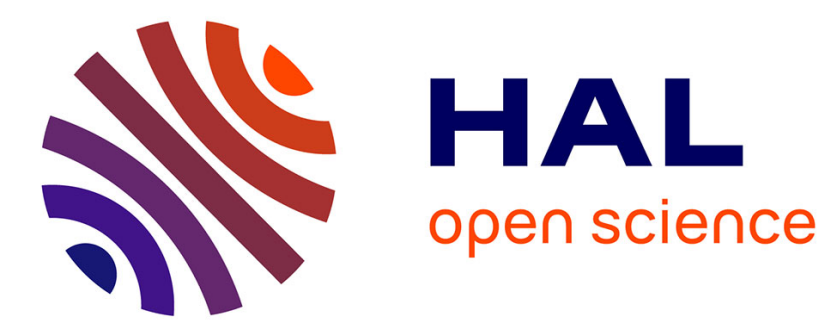

\title{
Crosslinkable dextrin-coated latex via surfactant-free emulsion polymerization
}

\author{
Mohamed Aouay, Albert Magnin, Jean-Luc Putaux, Sami Boufi
}

\section{To cite this version:}

Mohamed Aouay, Albert Magnin, Jean-Luc Putaux, Sami Boufi. Crosslinkable dextrin-coated latex via surfactant-free emulsion polymerization. Colloids and Surfaces A: Physicochemical and Engineering Aspects, 2022, 632, pp.127776. 10.1016/j.colsurfa.2021.127776 . hal-03418528

\section{HAL Id: hal-03418528 \\ https://cnrs.hal.science/hal-03418528}

Submitted on 7 Nov 2021

HAL is a multi-disciplinary open access archive for the deposit and dissemination of scientific research documents, whether they are published or not. The documents may come from teaching and research institutions in France or abroad, or from public or private research centers.
L'archive ouverte pluridisciplinaire HAL, est destinée au dépôt et à la diffusion de documents scientifiques de niveau recherche, publiés ou non, émanant des établissements d'enseignement et de recherche français ou étrangers, des laboratoires publics ou privés. 


\title{
Crosslinkable dextrin-coated latex via surfactant-free emulsion
}

\section{polymerization}

\author{
Mohamed Aouay ${ }^{\mathrm{a}}$, Albert Magnin ${ }^{\mathrm{b}}$, Jean-Luc Putaux ${ }^{\mathrm{c}}$, Sami Boufia, ${ }^{\mathrm{a}}$ \\ ${ }^{a}$ University of Sfax, LMSE, Faculty of Science, BP 802, 3018 Sfax, Tunisia \\ ${ }^{\mathrm{b}}$ Univ. Grenoble Alpes, CNRS, Grenoble INP, LRP, F-38000 Grenoble, France \\ ${ }^{\mathrm{c}}$ Univ. Grenoble Alpes, CNRS, CERMAV, F-38000 Grenoble, France
}

*Corresponding author: e-mail:sami.boufi@fss.rnu.tn

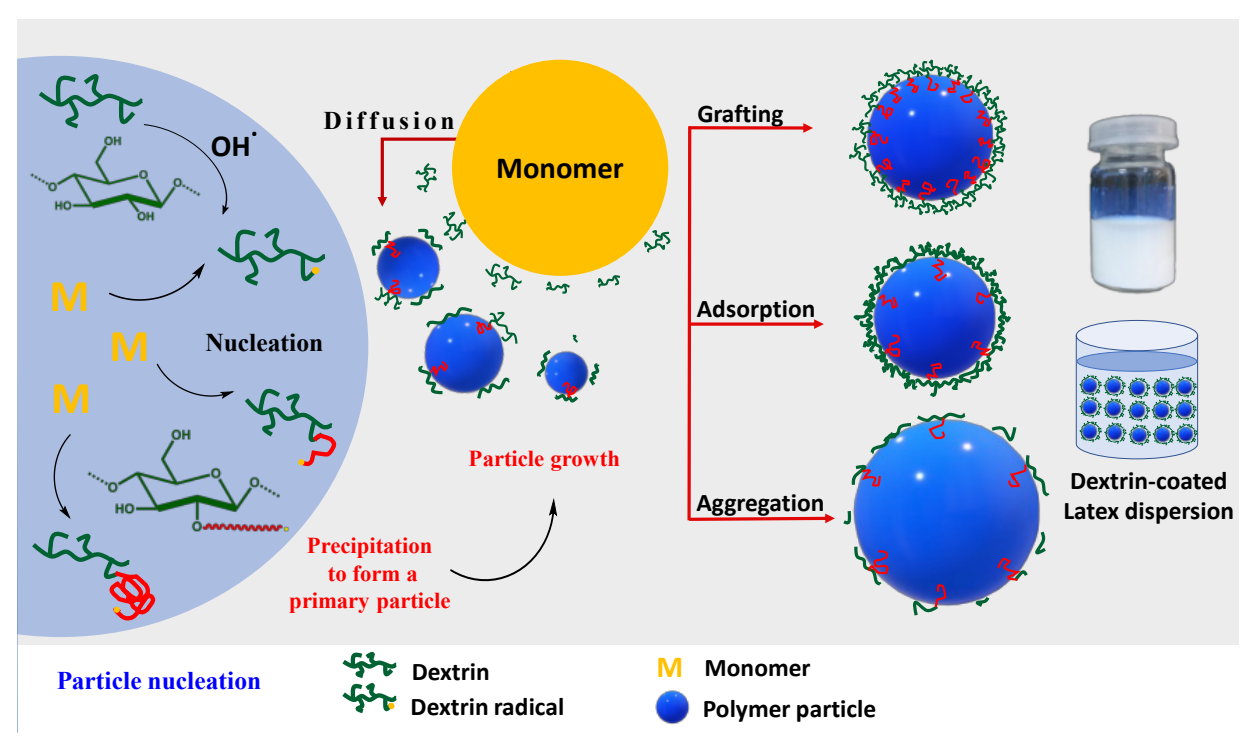

Dextrin-functionalized latex dispersion produced by emulsion polymerization of acrylic, vinylic or methacrylic monomers in the absence of surfactants

Published in: Colloids and Surfaces A 632 (2022), 127776

https://doi.org/10.1016/j.colsurfa.2021.127776 


\begin{abstract}
Emulsion polymerization remains the most attractive method to produce waterborne dispersions for coatings and adhesives, thanks to the use of water as dispersion medium. The possibility to replace the surfactants necessary for the stabilization by biopolymers would make this polymerization route even more attractive to alleviate the shortcomings of surfactants. Herein, dextrins were used as sole stabilizer to produce stable latex dispersions by emulsion polymerization with solid contents up to $55 \mathrm{wt} \%$ and narrow size distributions. The $\mathrm{H}_{2} \mathrm{O}_{2}$ /ascorbic acid redox initiator was found to be the most effective, ensuring a complete polymerization at $50{ }^{\circ} \mathrm{C}$ within $3-4 \mathrm{~h}$, giving rise to dextrin-functionalized polymer latexes with a particle size between 150 to $600 \mathrm{~nm}$. The stabilization was explained by the coating of the polymer particles with a chemically bound layer of dextrins, forming a steric barrier. The functionalization of the latex particles by dextrins was exploited to induce a post-crosslinking of the polymer by the inclusion of additives capable of reacting with dextrins. As application, a crosslinkable pressure-sensitive adhesive was prepared and used without any additive. Given the biobased origin of the dextrins and their availability, their use as sole stabilizer in emulsion polymerization is promising to produce waterborne latex dispersions for coatings, adhesives, inks, drug delivery, and textiles.
\end{abstract}

Keywords: dextrins; emulsion polymerization; stabilization; latex. 


\section{Introduction}

With growing concern over limiting emissions of volatile organic compounds (VOCs), emulsion polymerization has seen an increasing interest to produce latexes for waterborne coatings, adhesives or inks as a replacement for their solvent-based counterparts. This polymerization route offers numerous advantages [1], including the ease of heat removal during the polymerization, the low viscosity of the dispersion at high solid content from 40 to $60 \mathrm{wt} \%$, the possibility to easily separate the polymer by coagulation, the high polymerization rate without imparting the molecular weight, the environmentally friendly process as no organic solvent is used nor emitted, and the facility to scale-up without high investment.

In conventional emulsion polymerization, the addition of surfactants is a prerequisite to produce colloidally stable latex dispersions. By lowering the interfacial tension, the surfactant emulsifies the monomer and stabilizes the polymer particles during the polymerization and storage by increasing the electrostatic or steric repulsion between the particles. However, the presence of surfactant in the polymer dispersion can also have a detrimental effect on the properties of the final product after removal of water, such as the sensitivity to water and the alteration of the optical properties (transparency and gloss) of films when the latex was used in coatings [2] Additional drawbacks are cellular irritation in biomedical applications and environmental pollution resulting from the leaching out of the surfactant when the latex is used as a binder for architectural coatings [3].

Three alternatives might be adopted to prevent using conventional surfactants in emulsion polymerization. The first one consists in running the polymerization in the absence of any added surfactant via soap-free emulsion polymerization [4]. However, the resulting polymer dispersion suffers from a poor colloidal stability, a low solid content $(<20 \mathrm{wt} \%)$ and an ionic initiator is needed to impart surface charges on the particle surface [5]. The second alternative is to use a reactive emulsifier that can covalently attach to the polymer particle so that it can neither be desorbed nor migrate away from the film after the coalescence of polymer particles. This can be achieved by using a surface-active monomer (surfmer), via a surface-active transfer agent (transurf), or surface-active initiators (inisurfs) [6]. The third possibility is to use solid particles to stabilize so-called Pickering emulsions. In this stabilization mode, particles partially wetting oil and water provide a steric barrier against coalescence by adsorbing at the oil-water interface. This approach has been raising interest over the last decade, especially for biobased solid nanoparticles, the presence of which induced specific functionalities in addition to their stabilizing effect [7]. 
Driven by the growing demand for natural, environmentally-friendly and safe additives, polysaccharides have been gaining increasing attention as natural emulsifiers/stabilizers in the food, cosmetic and pharmaceutical industries. In fact, most polysaccharides do not act as true emulsifiers as they do not have much tendency to adsorb at fluid interfaces and enhance the emulsion stability by gelling or increasing the viscosity of the aqueous continuous phase, slowing down the droplet movement and preventing the droplets from interacting with each other $[8,9,10]$. Only a limited number of polysaccharides exhibit a surface/interfacial activity allowing their adsorption at the oil-water interface. Among them, gum Arabic can be mentioned, as well as chemically modified starch, galactomannan hydrocolloids, and acetylated pectin from sugar beet, that enhance the stabilization efficiency by adsorbing at the oil/droplet interface and provide effective steric and electrostatic effects [11].

There is a renewed interest in the use of polysaccharides as surfactants/stabilizers in emulsion polymerization, most specifically in surfactant-free emulsion polymerization where no surfactant other than the polysaccharide is added to ensure the long-term stabilization of the polymer particles and generate stable latex dispersions with a high solid content compatible with industrial applications (i.e. from 35 to $60 \mathrm{wt} \%$ ) and with the polysaccharide coating the polymer particles. A recent review on the latest progress in the synthesis of carbohydratefunctionalized hybrid latex particles was published by Smeets et al. [12]. Beyond the development of environmentally-friendly polymerization processes, the interest in the use of polysaccharides in surfactant-free emulsion polymerization to elaborate polysaccharide-coated latex nanoparticles is motivated by numerous benefits, including the increase in the biocontent of the synthetic latex, possibilities of applications in drug-delivery for various antibiotics [13], producing bioactive latex particles [14], and for industrial applications such as paper manufacturing [15]. Another possibility is to prepare hybrid latexes stabilized with biobased nanoparticles such as cellulose nanocrystals (CNCs) [16], starch nanocrystals (SNCs) [17] or chitin nanocrystals (ChNCs) [18].

Thanks to its water solubility, industrial availability and the wide range of physical and chemical modifications, starch and starch derivatives were among the most studied polysaccharide stabilizers in emulsion polymerization of a number of acrylic and vinylic monomers [19,20,21,22]. The latest progress concerning the use of starch in emulsion polymerization either as a colloidal stabilizer, reactive polymer or as a filler to achieve a target grafting performance or to incorporate starch in latex formulations for the replacement of synthetic polymers, has been recently reviewed [23]. Dextran, a polysaccharide synthesized by a number of bacteria and widely used in the pharmaceutical industry, has also drawn attention 
to produce dextran-coated latex particles via emulsion polymerization. In spite of the lack of surface-active properties, dextran was successfully used as sole stabilizer in the emulsion polymerization of styrene, yielding stable polymer particles coated with a permanently grafted dextran layer at their surface [24].

Dextrins are water-soluble low-molecular weight polysaccharides produced by the partial acid hydrolysis of native starch, and composed of D-glucosyl units linked by $\alpha(1 \rightarrow 4)$ and $\alpha(1 \rightarrow 6)$ glycosidic bonds. Owing to their water solubility, low cost, commercial availability, non-cytotoxicity and biodegradability, dextrins find widespread uses in various industrial applications [25] like food processing, textile coating, adhesives cosmetics, and paper, among others. These applications are mainly based on the dextrin water solubility and effective adhesion to paper and board. Only a limited number of works have reported on the potential use of dextrins as a stabilizer in heterogeneous polymerization, in replacement of synthetic surfactants. Recently, a commercial-grade maltodextrin was used as stabilizer in the soap-free emulsion polymerization of the three-monomer system butyl acrylate-styrene-methacrylic acid [26]. It was suggested that both physically adsorbed maltodextrins and chemically grafted maltodextrins contributed to the steric stabilization of the polymer particles.

The present paper describes the preparation of dextrin-coated polymer latexes by direct emulsion polymerization of acrylic monomers using dextrins as sole stabilizer. In spite of the lack of surface-active properties of dextrins, stable polymer dispersions with solid contents up to $50 \mathrm{wt} \%$, with dextrins chemically grafted at the particle surface were produced and mechanisms for the stabilization by dextrins and the growth of polymer particles were proposed. In the present study, the emphasis was put on the key role of the initiator system in governing the particle size of the latex dispersion as well as the stability of the dispersion. In addition, we have demonstrated that the presence of dextrins coating the latex particles might introduce additional functionalities to the latex dispersion, taking advantage of the chemistry of dextrins, and the presence of a high number of hydroxyl groups. All these aspects of the work have not been reported so far in the literature.

\section{Experimental section}

\subsection{Materials}

Butyl methacrylate (BMA), methyl methacrylate (MMA), styrene (STY), butyl acrylate (BA), vinyl acetate (VAM), ethylhexyl acrylate (EHA), $\mathrm{H}_{2} \mathrm{O}_{2}(30 \%)$, potassium persulfate (KPS), ascorbic acid (AA), 2,2'-Azobis(2-methylpropionamidine) dihydrochloride (V-50), 
Dioctyl sulfosuccinate sodium salt (DOSS), uranyl acetate and borax were purchased from Sigma-Aldrich and used without further purification. Commercial dextrins were purchased from Avebe (The Netherlands), and were used as received without further purification. They differed by their molecular weight and solution viscosity: Avedex 75MF14 with a high molecular weight and viscosity (HV), Avedex 48MC14 with a medium molecular weight and viscosity (MV) and Avedex 28LA21 with a low molecular weight and viscosity (LV). Demineralized water was used in the polymerization reaction.

\subsection{Dextrin solution preparation}

A dextrin solution with a solid content (SC) of $10 \mathrm{wt} \%$ was prepared by dissolving $10 \mathrm{~g}$ of dextrins in $90 \mathrm{~mL}$ water and heating at $70{ }^{\circ} \mathrm{C}$ until complete dissolution. The $\mathrm{pH}$ of the solution was adjusted to $7-7.5$ by the addition of a $0.02 \mathrm{M}$ ammonia solution.

\subsection{Emulsion polymerization}

The emulsion polymerization was run under batch condition in a three-neck 250 -mL roundbottom flask placed in a thermostated bath and equipped with a magnetic stirrer, a condenser, and two inlets for adding initiator solution and aliquot sampling. The KPS, $\mathrm{H}_{2} \mathrm{O}_{2}$ or $\mathrm{H}_{2} \mathrm{O}_{2} / A A$ were used as initiator at a concentration of $2 \mathrm{wt} \%$ (based on monomer content) and the polymerization was conducted at a constant temperature between 50 to $80^{\circ} \mathrm{C}$ depending on the initiation system $\left(80{ }^{\circ} \mathrm{C}\right.$ when KPS and $\mathrm{H}_{2} \mathrm{O}_{2}$ were used and at $50{ }^{\circ} \mathrm{C}$ with the $\mathrm{H}_{2} \mathrm{O}_{2} / \mathrm{AA}$ redox initiation system). The typical procedure was the following: the monomer was mixed with the dextrin solution (at different concentration between 4 to $12 \mathrm{wt} \%$ based on monomer content) and the required volume of water was added to reach the target SC. After stirring the mixture, and flushing with $\mathrm{N}_{2}$ to remove dissolved oxygen, the polymerization was initiated by continuous injection of the initiator solution. When AA was used in the redox-initiation, it was first added to the monomer-dextrin mixture. The polymerization was conducted at constant temperature by continuous injection of the initiator during $1.5 \mathrm{~h}$, and further pursued (during 2 to $4 \mathrm{~h}$, depending on the monomer) to ensure a complete consumption of the monomer. The end of the polymerization was assessed by controlling the solid content (SC) in the latex through gravimetric analysis. To prevent bacterial growth, $\mathrm{NaN}_{3}(0.1 \%)$ was added to the polymer dispersion. A hydroquinone solution $(0.5 \%)$ was added to the samples prior to drying to stop further polymerization. The conversion degree of the polymerization was determined by taking samples at different times, and oven-drying them to remove water and unreacted monomer. A detailed example of the polymerization protocol is given in Supplementary Material. 


\subsection{Polymer particle size}

The average diameter of polymer particles in the emulsion was determined using dynamic light scattering (Malvern Zetasizer Nano S, Malvern Instruments Ltd., Malvern, UK) at a fixed scattering angle of $173^{\circ}$. The latex dispersion was diluted about 10 times with water before measurements. The particle size was expressed as a Z-average of the diameter of an equivalent hard sphere with the same diffusion coefficient as the particle under analysis. The measurements were performed three times for each sample, and the average value was retained as the particle size. The particle number $\mathrm{N}_{\mathrm{p}}$ was calculated from DLS data using Eq. 1:

$$
N_{p}=\frac{6 C_{p}}{\left(\rho_{p} \pi D_{p}^{3} 10^{-21}\right)} \quad \text { Eq. } 1
$$

with $N_{p}$ being the number of particles $\left(\mathrm{cm}^{-3}\right), C_{p}$ the polymer concentration $\left(\mathrm{g} \mathrm{mL}^{-1}\right), D_{p}$ the average particle size $(\mathrm{nm})$, and $\rho_{p}$ the polymer density $\left(\mathrm{g} \mathrm{cm}^{-3}\right)$.

\subsection{Grafted dextrins}

The fraction of dextrins chemically anchored to the polymer particles was obtained by extensive Soxhlet extraction, of lyophilized sample latex, using water for $24 \mathrm{~h}$ to remove the fraction of ungrafted dextrins. The grafting degree $\left(G_{d e x t}\right)$ with respect to the amount of added dextrins was calculated on the basis of gravimetric data as follows:

$$
G_{\text {dext }}(\%)=\frac{m_{f}}{m_{i}} \times 100 \quad \text { Eq. } 2
$$

where $m_{i}$ is the weight of added dextrins, and $m_{f}$ is the weight of residual dextrins.

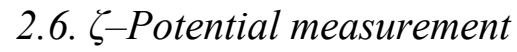

A laser Doppler electrophoresis apparatus (Malvern NanoZetasizer ZS, UK) was used to measure the $\zeta$-potential at $25{ }^{\circ} \mathrm{C}$. For each sample, the measurement was done in triplicates.

\subsection{Film preparation}

The films were prepared by casting the polymer dispersion in a Teflon mold and storing at $40{ }^{\circ} \mathrm{C}$ until complete evaporation of water and film-formation process. For ex-situ mixing, a PBMA latex at $30 \mathrm{wt} \% \mathrm{SC}$ was prepared in the presence of dioctyl sulfanosuccinate sodium salt (DOSS) (3 $\mathrm{wt} \%$ with respect to monomer content) and mixed with the aqueous dextrin solution, before casting and drying.

\section{8. ${ }^{13}$ C CP-MAS NMR}

The NMR spectrum was recorded from the polymer powder after extensive Soxhlet extraction of the freeze dried-dispersion. The polymer was recovered from the latex after 
centrifugation at $8000 \mathrm{rpm}$ for $20 \mathrm{~min}$ to keep the non-adsorbed dextrins in the aqueous phase. The latex powder was poured into a zirconia rotor. Solid-state ${ }^{13} \mathrm{C}$ NMR analyses were performed with a Bruker Avance III $400 \mathrm{MHz}$ spectrometer $\left({ }^{13} \mathrm{C}\right.$ frequency of $\left.100.6 \mathrm{MHz}\right)$ using magic angle spinning (MAS) and cross-polarization (CP). The spinning speed was set at $12 \mathrm{kHz}$, with a sweep width of $29761 \mathrm{~Hz}$ and a recycle delay of $2 \mathrm{~s}$. Each spectrum was averaged over about 6000 scans. The ${ }^{13} \mathrm{C}$ chemical shifts were calibrated with respect to that of the glycine carboxyl group (176.03 ppm).

\subsection{Electron microscopy}

Drops of dilute latex suspensions were deposited on carbon tape and allowed to dry. The specimens were coated with $\mathrm{Au} / \mathrm{Pd}$ in a Baltec MED-020 sputter coater and observed in secondary electron mode in Thermo Scientific Quanta 250 scanning electron microscope equipped with a field emission gun and operating at $2.5 \mathrm{kV}$. Droplets of dilute latex suspensions were deposited on glow-discharged carbon-coated copper grids and allowed to dry after negative staining with $2 \%$ uranyl acetate. The preparations were observed with a JEOL JEM2100 Plus transmission electron microscope operating at $200 \mathrm{kV}$. Images were recorded with a Gatan Rio 16 camera.

\subsection{Rheological measurements}

A stress-controlled Rheometer (Kinexus Pro+, Malvern Instruments, UK) with a cone plate geometry (cone angle, $2^{\circ}$; diameter, $20 \mathrm{~mm}$; truncation, $56 \mu \mathrm{m}$ ) was used to measure the rheological properties of latex dispersions at $25{ }^{\circ} \mathrm{C}$ using Peltier heating system. The steadystate viscosity was investigated at shear rates ranging from 0.01 to $100 \mathrm{~s}^{-1}$. Under dynamic mode, the linear domain was first determined by a sweep of the storage modulus $\mathrm{G}^{\prime}$ and loss modulus G" vs. strain. The strain range extended from 0.001 to $10 \%$. Then, a frequency sweep at a fixed strain in the elastic linear domain was made. To prevent any risk of slippage, the surfaces of rheometric tools have been roughened.

\subsection{Pressure-sensitive adhesive (PSA)}

For PSA application, a latex dispersion based on EHA was prepared by emulsion polymerization at $80{ }^{\circ} \mathrm{C}$ in the presence of $8 \mathrm{wt} \%$ dextrins (based on monomer content) at 30 $\mathrm{wt} \% \mathrm{SC}$, using KPS as initiator. For comparison purpose, the same latex dispersion was prepared by replacing the total amount of dextrins by sodium dioctyl sulfanosuccinate (DOSS) (3 wt $\%$ with respect to monomer content) as an anionic surfactant stabilizer for the emulsion polymerization. 


\subsection{2. $180^{\circ}$ Peel strength and rheology analysis}

The PSA based on polybutylacrylate (PBA) latex was coated on one side of a Corona-treated PP films of about $100 \mu \mathrm{m}$ thickness, using a micrometer variable applicator at a thickness of about $100 \mu \mathrm{m}$, and was glued with the second film after drying for $1 \mathrm{~h}$ at room temperature. The adhesive performance was evaluated by $180^{\circ}$-peel adhesion by attaching the two parts of the film to the load cell using a tension clamp to measure the force necessary to strip off the two adherent films with $180^{\circ}$ angle at a peel rate of at a peel rate of $300 \mathrm{~mm} \mathrm{~min}^{-1}$, using a universal testing machine (Instron).

Rheological properties were investigated using a controlled stress rheometer (Pro+ Kinexus from Malvern) with a plate-plate configuration $(10 \mathrm{~mm}$ in diameter and a gap of $500 \mu \mathrm{m})$ at $25{ }^{\circ} \mathrm{C}$. First, an amplitude sweep in the $0.1-100 \%$ deformation range was carried out at a frequency of $1 \mathrm{~Hz}$ to define the linear viscoelastic region (LVE) of the acrylic PSA. Then, frequency sweeps from 0.01 to $10 \mathrm{~Hz}$ were performed at a strain of $1 \%$ within the linear domain where the storage $\left(G^{\prime}\right)$ and loss $\left(G^{\prime \prime}\right)$ moduli were recorded.

\section{Results and discussion}

\subsection{Emulsion polymerization}

The emulsion polymerization of BMA in the presence of dextrins as sole stabilizer, using the $\mathrm{H}_{2} \mathrm{O}_{2} / \mathrm{AA}$ redox imitator system at $50{ }^{\circ} \mathrm{C}$ and at a SC from 20 to $55 \mathrm{wt} \%$ resulted in stable latex dispersions, the polymerization being completed within 3-4 h. No polymerization took place in the absence of dextrins, even after $8 \mathrm{~h}$ stirring at $50{ }^{\circ} \mathrm{C}$, confirming the key role of dextrins in the success of the emulsion polymerization. No emulsion was obtained prior to the polymerization and a rapid phase separation of the monomer was observed within $30 \mathrm{~min}$ from the interruption of the magnetic stirring. Once the initiator was added, the mixture rapidly turned to milky white within 15-30 min of the onset of the polymerization, giving rise, after full conversion of the monomer, to a stable white fluid emulsion free from any coagulum as the content in dextrins was in the 4-12 wt $\%$ range (based on the weight of monomer). As shown in Figure 1A, the amount of dextrins significantly affected the particle size of the polymer dispersion, mostly between 2 to $8 \mathrm{wt} \%$ dextrins, where the polymer particle size steadily decreased with increasing dextrin concentration. At $2 \mathrm{wt} \%$ dextrins, the mean particle size was around $800 \mathrm{~nm}$ and decreased to about $210 \mathrm{~nm}$ as the dextrin content increased to $8 \mathrm{wt} \%$ (Figure 1B). For all polymerization experiments, the latex dispersion exhibited a unimodal particle size distribution with a PDI lower than 0.1 , which is indicative of a narrow dispersion. 

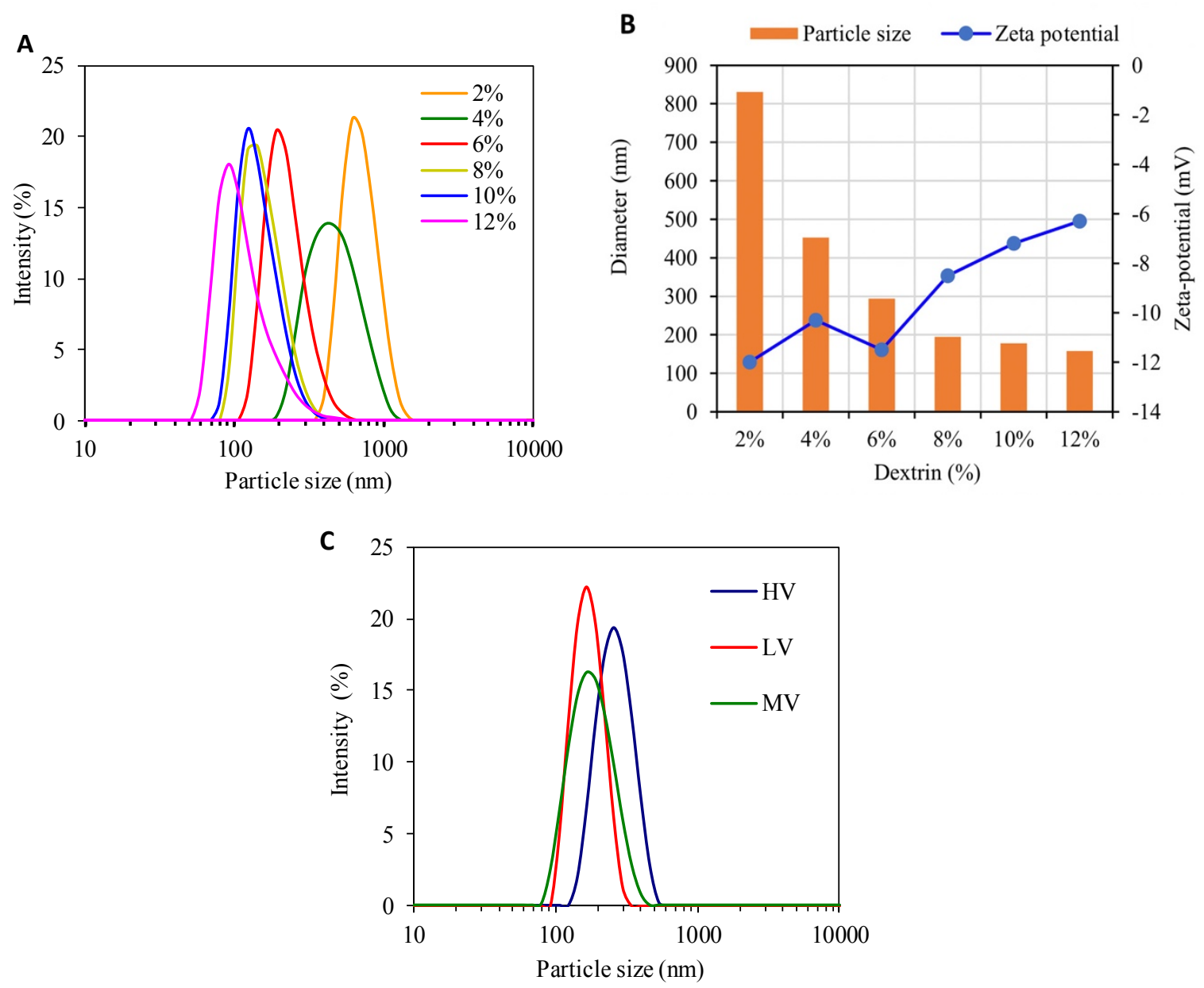

Figure 1. (A) Particle size distribution, (B) mean-particle size and $\zeta$-potential of PBMA latexes prepared in the presence of different dextrin contents, and (C) particle-size distribution of PBMA latexes prepared in the presence of $6 \mathrm{wt} \%$ dextrins of different molecular weights (polymerization run at $50{ }^{\circ} \mathrm{C}$ in the presence of $2 \mathrm{wt} \%$ (based on monomer content) $\mathrm{H}_{2} \mathrm{O}_{2} / \mathrm{AA}$ initiator).

The unsuccessful polymerization in the absence of dextrins and the correlation between the particle size and the amount of dextrins demonstrate the effectiveness of dextrins in ensuring colloidal stabilization during the emulsion polymerization of BMA. These results agree with those recently reported by Ferrari et al. [22] where stable latex dispersions were obtained for the emulsion polymerization of butyl acrylate-styrene and methacrylic acid (45/50/5 wt \%). Although the stabilizing role of dextrins was highlighted, the presence of methacrylic acid would also contribute to the stabilization process by imparting negative charges on the surface of the polymer particles. 

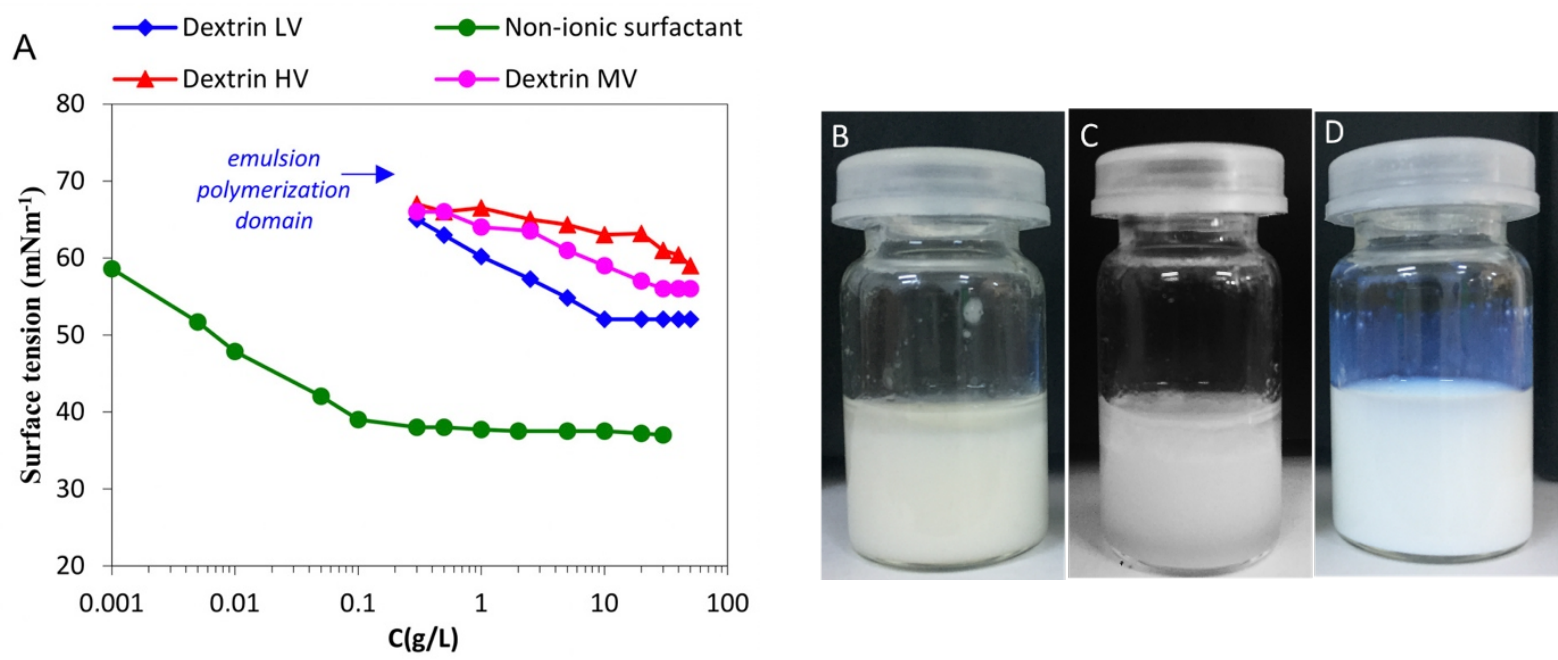

Figure 2. (A) Surface tension of aqueous dextrin solutions at different concentrations, and visual aspect of (B) emulsion of BMA in dextrin solution ( $8 \mathrm{wt} \%),(\mathrm{C})$ emulsion after the stirring was stopped, and (D) PBMA latex after emulsion polymerization. The LV-dextrin was used at $8 \mathrm{wt} \%$ and $30 \mathrm{wt} \% \mathrm{SC}$.

The colloidal stability was not strongly affected by the molecular weight of dextrins, since all three grades of dextrins (LV, MV and HV) resulted in stable polymer latex dispersions (Figure 1C). However, the dextrins with the lowest molecular weight seem to have yielded the smallest particles, around $160 \mathrm{~nm}$ at $8 \mathrm{wt} \% \mathrm{LV}$-dextrins against $255 \mathrm{~nm}$ when high molecular weight HV-dextrins were used. In addition, the absolute value of the $\zeta$-potential of the polymer particles remained relatively low, increasing from $-12 \mathrm{mV}$ to $-6 \mathrm{mV}$ as the dextrin content increased from 2 to $12 \mathrm{wt} \%$, respectively. This means that the stabilization of polymer particles during polymerization was not driven by an electrostatic barrier and the dextrin content did not significantly affect the surface charge of the polymer particle. The decrease in the absolute value of the $\zeta$-potential observed for dextrin contents over $6 \mathrm{wt} \%$ suggests that the polymer particles became less charged with increasing dextrin content. The initiation system as well as the monomer type also affected the particle size and the kinetics of polymerization as shown in Table 1. The lowest polymerization rate was noted in the presence of a cationic Azo V-50 initiator giving rise to a polymer dispersion with the largest particles, around $600 \mathrm{~nm}$. KPS, which is the typical initiator widely used in emulsion polymerization, was also effective in running the polymerization within $4 \mathrm{~h}$ at $80^{\circ} \mathrm{C}$, but resulted in a polymer dispersion with a higher particle size in comparison with the $\mathrm{H}_{2} \mathrm{O}_{2}$ /AA initiator. This difference was presumably related to the mechanism of stabilization of dextrins as will be discussed in the following.

From Figure $2 \mathbf{A}$ that depicts the evolution of the surface tension $\left(\gamma_{\mathrm{L}}\right)$ of dextrin solutions with concentration, it can be seen that dextrins did not manifest any obvious surface activity in 
aqueous solution, especially for $\mathrm{HV}$ - and MV-grade dextrins, where $\gamma_{\mathrm{L}}$ did not notably decrease up to a concentration of $50 \mathrm{~g} \mathrm{~L}^{-1}$. The lowest $\gamma_{\mathrm{L}}$ was observed for low molecular weight LV-dextrins over a concentration of concentration of $10 \mathrm{~g} \mathrm{~L}^{-1}$, reaching a plateau in $\gamma_{\mathrm{L}}$ at $51 \mathrm{mN} \mathrm{m}^{-1}$, which might indicate a possible adsorption of LV-dextrins at the air-water over a critical concentration. However, this surface activity is low in comparison to that of a non-ionic emulsifying surfactant like Tween 80 for which a plateau around $35 \mathrm{mN} \mathrm{m}^{-1}$ is reached at low concentration around $0.1 \mathrm{~g} \mathrm{~L}^{-1}$. Moreover, the range of dextrin concentration used in the present work for the emulsion polymerization (between 2 to $10 \mathrm{wt} \%$ based on monomer content, which corresponds at $30 \mathrm{wt} \% \mathrm{SC}$ to a dextrin concentration between 0.8 and $4 \mathrm{wt} \%$ ) is located far from the plateau reached by $\gamma_{\mathrm{L}}$, ruling out any possible contribution of the surface activity in the emulsion polymerization in the presence of dextrins. It is worth remembering that no emulsion was formed after mixing the monomer with an aqueous dextrin solution at a concentration ranging from 0.5 to $5 \mathrm{~g} \mathrm{~L}^{-1}$ as a phase separation of the monomer rapidly occurred (within $30 \mathrm{~min}$ ) once stirring was stopped, as can be seen in Figure 2B.

Table 1: Emulsion polymerization data in the presence of different initiators and monomers ( $8 \mathrm{wt} \%$ dextrins; $2 \%$ initiator (based on monomer content).

\begin{tabular}{ccccccc}
\hline Monomer & Initiator system & $\begin{array}{c}\text { Polymerization } \\
\text { Time }(\mathrm{h})^{\mathrm{a}}\end{array}$ & $\begin{array}{c}G_{\text {dex }} \\
(\%)^{\mathrm{b}}\end{array}$ & $\begin{array}{c}\text { Temp } \\
\left({ }^{\circ} \mathrm{C}\right)^{\mathrm{c}}\end{array}$ & $\begin{array}{c}\mathrm{D}_{\mathrm{p}} \\
(\mathrm{nm})\end{array}$ & $\begin{array}{c}\zeta_{\text {-potential }} \\
(\mathrm{mV})\end{array}$ \\
\hline \multirow{2}{*}{$\mathrm{BMA}$} & $\mathrm{H}_{2} \mathrm{O}_{2} / \mathrm{AA}$ & 3 & $70 \pm 5$ & 50 & 192 & -6 \\
$\mathrm{KPS}$ & $\mathrm{V}-50$ & 6 & $31 \pm 4$ & 70 & 609 & +18 \\
$\mathrm{MMA}$ & $\mathrm{H}_{2} \mathrm{O}_{2} / \mathrm{AA}$ & 4 & $67 \pm 0.5$ & 50 & 188 & -9 \\
$\mathrm{Styrene}$ & $\mathrm{KPS}$ & 3 & & 80 & 210 & -19 \\
$\mathrm{BA}$ & $\mathrm{KPS}$ & 4 & & 80 & 180 & -14 \\
$\mathrm{VAM}$ & $\mathrm{KPS}$ & 6 & & 80 & 550 & -18 \\
VAM & $\mathrm{H}_{2} \mathrm{O}_{2} / \mathrm{AA}$ & - & 50 & - & \\
EHA/BMA & $\mathrm{KPS}$ & 4 & & 80 & 290 & -21 \\
\hline
\end{tabular}

${ }^{\text {a }}$ Time needed to reach a conversion exceeding $98 \%$

${ }^{\mathrm{b}}$ Amount of grafted dextrins with respect to added dextrins

${ }^{\mathrm{c}}$ Polymerization temperature

${ }^{\mathrm{d}}$ EHA/BMA (85/15) 
Referring to the work of Ferrari et al. [22] regarding the surfactant-free emulsion polymerization of butyl acrylate-styrene and methacrylic acid $(45 / 50 / 5 \mathrm{wt} \%)$ in the presence of maltodextrins, it was proposed that maltodextrins were physically adsorbed with a fraction being chemically grafted onto the polymer particles, forming a physical barrier against the aggregation of polymer particles. To gain more insight into the stabilizing mechanism of dextrins, three initiators differing by the structure of the generated radical species and by their hydrogen abstraction property were tested. Moreover, other monomers were tested to check whether the success of emulsion polymerization in the presence of dextrins could be extended to other monomers. The results were collected in Table 1, from which the following conclusions can be drawn: (i) the fraction of grafted dextrins strongly depends on the type of initiator, with the lowest grafting level achieved for Azo V-50 and KPS, reaching 31 and $40 \%$, respectively, while $70 \%$ of dextrins was grafted when $\mathrm{H}_{2} \mathrm{O}_{2} /$ AA redox initiator was used. (ii) The particle size seemed to follow a reverse trend compared to that of the fraction of grafted dextrins, with the highest mean size reached in the presence of V-50 initiator, followed by KPS and $\mathrm{H}_{2} \mathrm{O}_{2} / \mathrm{AA}$. (iii) At the same $\mathrm{SC}$ and for the same initiator, the particle size strongly depended on the monomer structure. Based on the above data, we can conclude that the grafting of dextrins plays a key role in the stabilization process during the growth of the polymer particles, presumably by generating a steric barrier preventing the particles from approaching below a critical distance.

The grafting of dextrins by the monomer took place via $\mathrm{H}$-abstraction by radical generated by the decomposition of the initiator in water, followed by monomer addition, turning the grafted dextrins into amphiphilic polymers in which the hydrophobic segment was formed by the grafted dextrins. The $\mathrm{H}$-abstraction may proceed from the hydroxyl group or $\mathrm{CH} / \mathrm{CH}_{2}(\mathrm{C} 3$ or C6 carbon of the glucose cycle). In fact, even though most of the literature data assumed that the $\mathrm{H}$-abstraction preferentially occurred from the hydroxyl group, the second option (ie. $\mathrm{H}$-abstraction from $\mathrm{CH}$ or $\mathrm{CH}_{2}$ ) should be the most favorable from a thermodynamic point of view since the oxygen-hydrogen bonds are stronger than secondary or tertiary carbonhydrogen bonds by $>30 \mathrm{~kJ} \mathrm{~mol}^{-1}$ [27] (Scheme 1). The grafted dextrins then attached to the polymer particle through four possible mechanisms: (i) aggregation with a nucleated polymer particle formed by initiation in the aqueous phase and collapse of growing chain once their size exceeded a critical DP, (ii) acting as a growth site to the nucleation of polymer particle, (iii) coupling with a macroradical or a primary particle, and (iv) entering into a monomer-swollen particle via its hydrophobic part. In all cases, the grafted dextrins should be chemically linked to the polymer particle with its hydrophobic part pointing inside the polymer particle and the 
hydrophilic chains dangling out into the water phase, providing sufficient physical barrier steric to overcome the van der Waals forces between neighboring particles. These different steps are depicted in Scheme 2. The key role of steric stabilization provided by the grafted dextrins is further supported by the low $\zeta$-potential of polymer particles when $\mathrm{H}_{2} \mathrm{O}_{2} / \mathrm{AA}$ was used as initiator $(\zeta$-potential $<-10 \mathrm{mV})$, and the highest particle size reached when KPS was used $\left(D_{p}=435 \mathrm{~nm}\right)$, despite the relatively high $\zeta$-potential of the polymer particles $(-23 \mathrm{mV})$, which would impart electrostatic repulsion. The low grafting efficiency in the presence of Azo V-50 initiator is likely due to the poor H-abstracting aptitude of the free radicals produced by the decomposition of azo, most likely because of the resonance-stabilization of the ensuing tertiary free radicals [28].

The contribution of homogeneous nucleation to the particle formation should also not be excluded. The radicals generated in the aqueous phase would react with dissolved monomers generating oligoradicals until a critical $\mathrm{z}$ length is reached. They would precipitate, forming a primary particle that becomes stabilized by dextrin adsorption. Another possibility for oligoradicals would be the entry into an existing polymer particle.

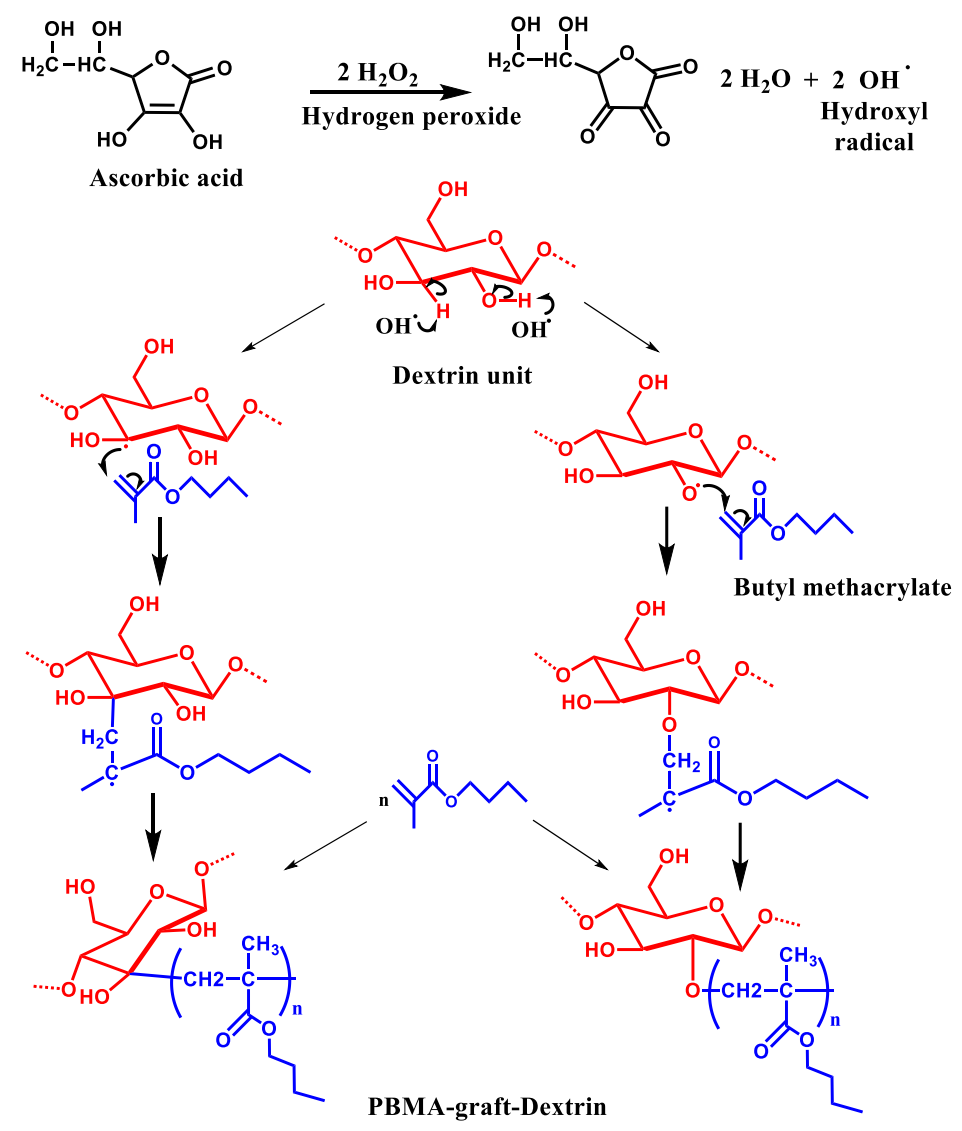

Scheme 1. Mechanism of grafting of dextrins in the emulsion polymerization of BMA using the $\mathrm{H}_{2} \mathrm{O}_{2} /$ AA redox initiator. 


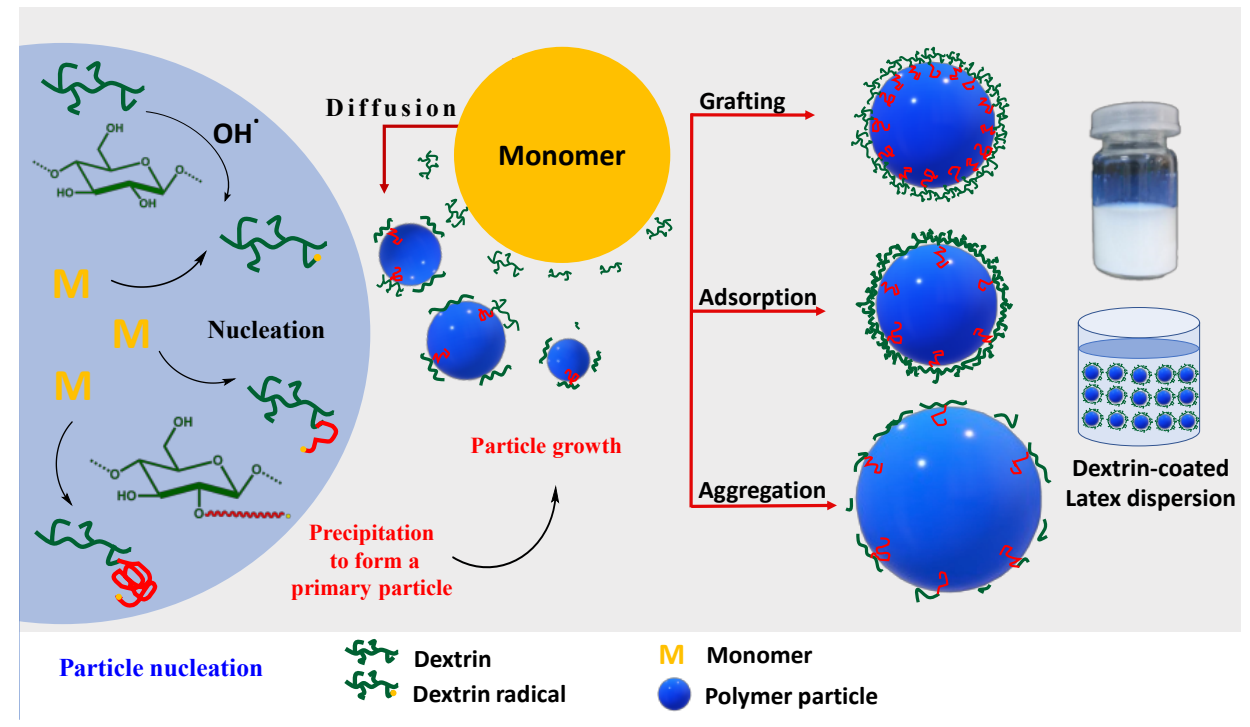

Scheme 2. Nucleation and growth in the emulsion polymerization in the presence of dextrins. The highlight was put on the different possibilities of the coating of polymer particles by dextrins, by either direct grafting, adsorption or particle aggregation.

It is worth mentioning that the films obtained from the PBMA latex after water evaporation and film-formation at $40{ }^{\circ} \mathrm{C}$ were completely transparent, free from any haze and with a transmittance exceeding $80 \%$, which indicates the intimate mixing of dextrins with PBMA (Figure 3A). Without effective grafting, the hydrophilic dextrins are incompatible with PBMA, resulting in a decrease in film transparency as shown in the photo of the PBMA film (Figure 3G) prepared by ex-situ mixing of the PBMA latex with a dextrin aqueous solution. The film is opaque with a significant decrease in transmittance to about $73 \%$ at $600 \mathrm{~nm}$, against $88 \%$ for the film prepared via in-situ polymerization in the presence of dextrins at the same content. The opacification of the film results from the lack of miscibility between hydrophobic PBMA and hydrophilic dextrins. The visual aspect of PBMA-dextrin films prepared by emulsion polymerization in the presence of dextrins or via mixing is shown in Figure 2B.

Further confirmation of the binding of dextrins to the polymer was provided by the CP-MAS NMR analysis. The spectra were recorded on latexes prepared following two protocols: the first one was to run the polymerization at low SC (around $5 \mathrm{wt} \%$ ) in the presence of equal amounts of dextrins and monomer in order to amplify the grafting reaction. The second one was the normal emulsion polymerization in the presence of $10 \mathrm{wt} \%$ dextrins using at $30 \mathrm{wt} \% \mathrm{SC}$. For this later run, MMA and STY (styrene) monomers were tested. The same redox $\mathrm{H}_{2} \mathrm{O}_{2} / \mathrm{AA}$ initiation system was adopted. The NMR spectrum was recorded from the polymer powder after centrifugation and extensive Soxhlet extraction of the freeze dried-dispersion to remove any physically adsorbed dextrin (Figure 4). In the presence of a high amount of dextrins 
(Figure 4A), the spectrum showed the PMMA chemical shifts at 15, 45, 50 and 56 ppm, corresponding to carbons $\mathrm{Ca}, \mathrm{Cb}, \mathrm{Cc}$ and $\mathrm{Cd}$, respectively, while the peaks at 102.5, 82.0, 72.4, 60.7 ppm, assigned to carbons $\mathrm{C} 1, \mathrm{C} 4, \mathrm{C} 2-3-5$, and $\mathrm{C} 6$ of the dextrins, respectively, attest of the presence of dextrins. In the sample recovered from conventional emulsion polymerization, the NMR peaks of dextrins were less visible and only the peak at 70-75 ppm was detected. The decrease in the intensity of dextrin peaks is likely due to the lower amount of dextrins with respect to PMMA. However, the presence of this peak confirmed the chemical binding of a fraction of dextrins to the polymer particles. It is worth mentioning that the grafting via the abstraction of a hydroxyl hydrogen by hydroxyl radicals has been reported in the literature for the grafting of polysaccharides such as starch and cellulose [29].
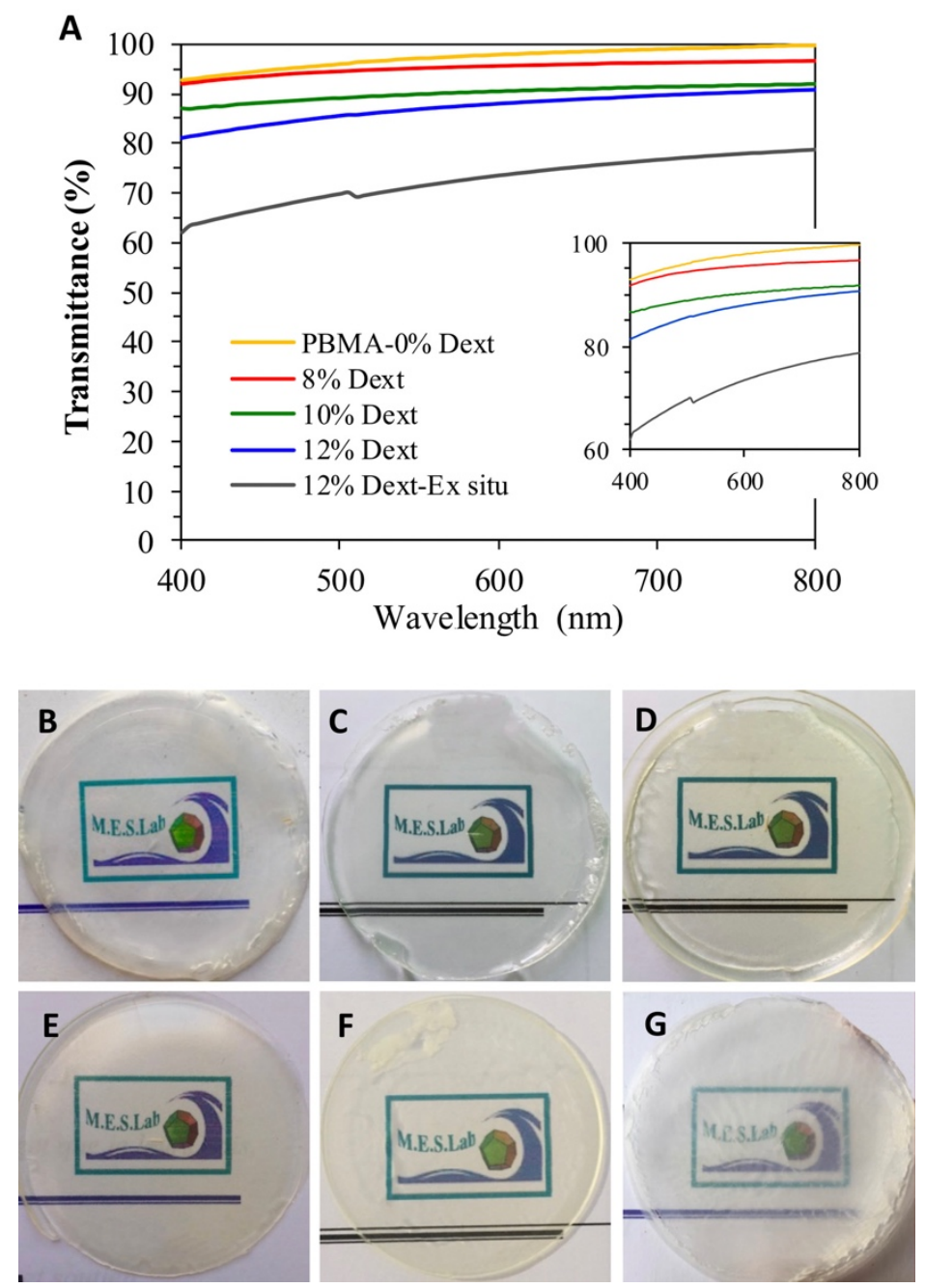

Figure 3. (A) Transmittance of PBMA films produced by emulsion polymerization in the presence of different amount of dextrins (PBMA-0\%Dex: film without dextrins); photos of the corresponding films obtained by simple casting and film-formation at $40{ }^{\circ} \mathrm{C}$ (B) PBMA- $0 \%$ Dex, (C) PBMA-6\%Dex, (D) PBMA-8\%Dex, (E) PBMA-10\%Dex, (F) PBMA-12\%Dex, and (G) PBMA-10\%Dex ex-situ. The film thickness was around $400 \mu \mathrm{m}$. 
A

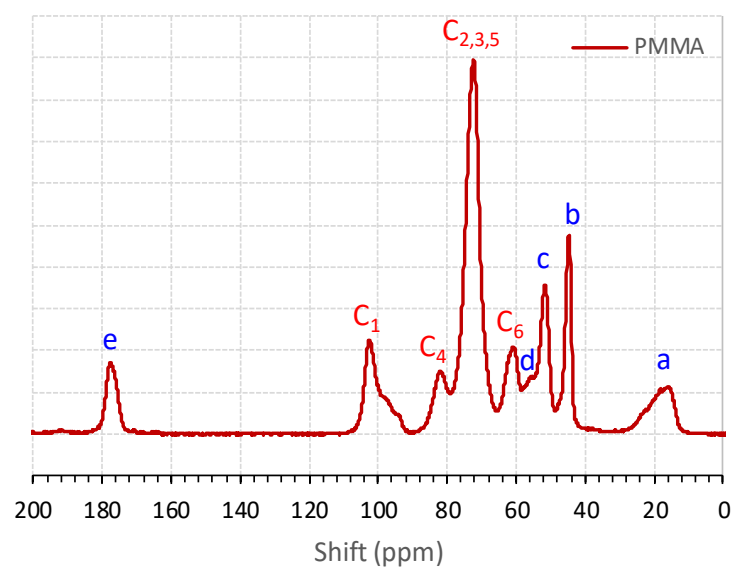

B

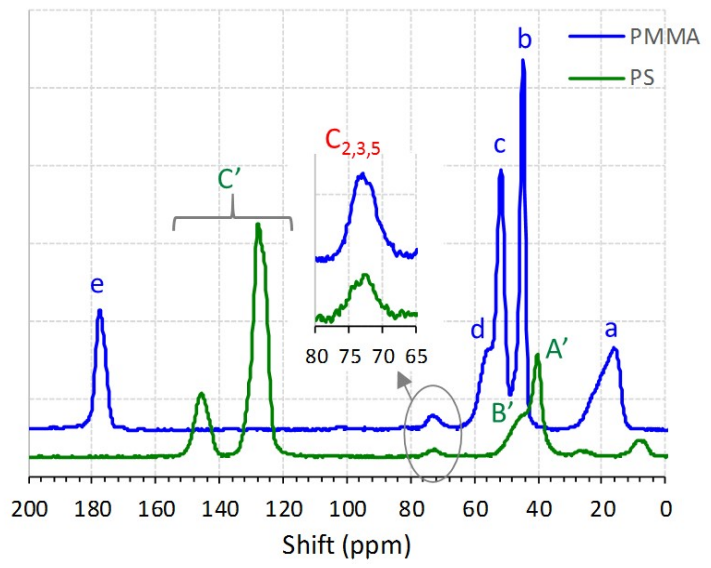

Dextrin

PMMA

PS
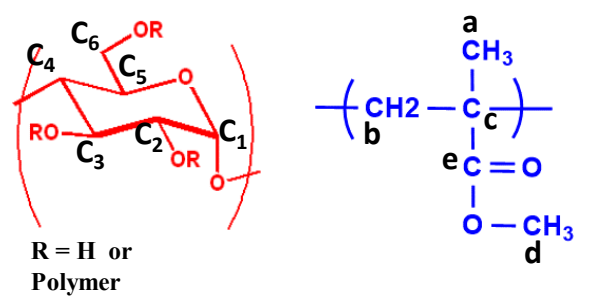

$\mathrm{C}_{\mathrm{C}^{\prime}}^{\mathrm{A}^{\prime}}$

Figure 4. ${ }^{13} \mathrm{C}$ CP-MAS spectra of PMMA and PSTY latexes prepared in the presence of dextrins using the $\mathrm{H}_{2} \mathrm{O}_{2} / \mathrm{AA}$ initiator: (A) polymerization run at $5 \mathrm{wt} \% \mathrm{SC}$ in the presence of 5 $\mathrm{wt} \%$ MMA and $5 \mathrm{wt} \%$ dextrins; (B) emulsion polymerization of MMA and STY at $30 \mathrm{wt} \% \mathrm{SC}$, with $10 \mathrm{wt} \%$ dextrins (with respect to monomer).
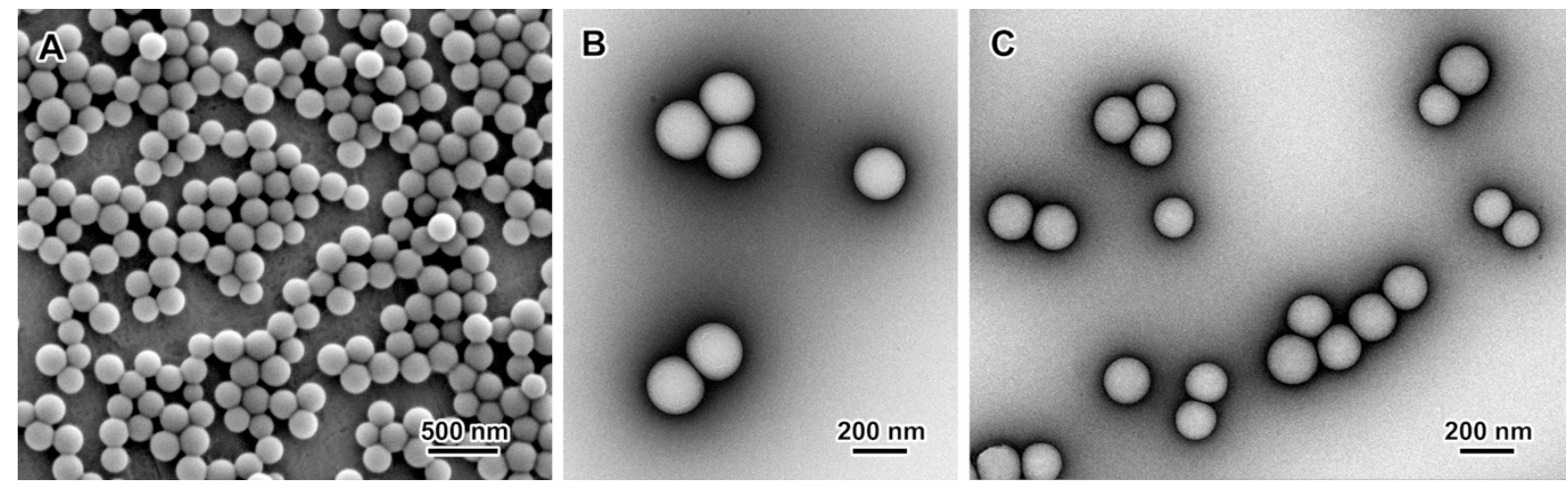

Figure 5. SEM (A) and TEM (B,C) images of PSTY (A,B) and PMMA (C) nanoparticles prepared in the presence of $8 \mathrm{wt} \%$ dextrins at $30 \mathrm{wt} \% \mathrm{SC}$. In $\mathrm{B}$ and $\mathrm{C}$, the preparations have been negatively stained with uranyl acetate.

The PSTY and PMMA latex particles were observed by SEM (Figure 5A) and TEM (Figure 5B,C), the other systems having a glass transition temperature $\left(\mathrm{T}_{\mathrm{g}}\right)$ too low to prevent any deformation upon sample preparation. The PSTY and PMMA particles prepared in the presence of $8 \mathrm{wt} \%$ dextrins and using $\mathrm{H}_{2} \mathrm{O}_{2} /$ AA redox initiator were spherical with a diameter ranging from 150 to $200 \mathrm{~nm}$, which is consistent with the DLS data (Table 1). 

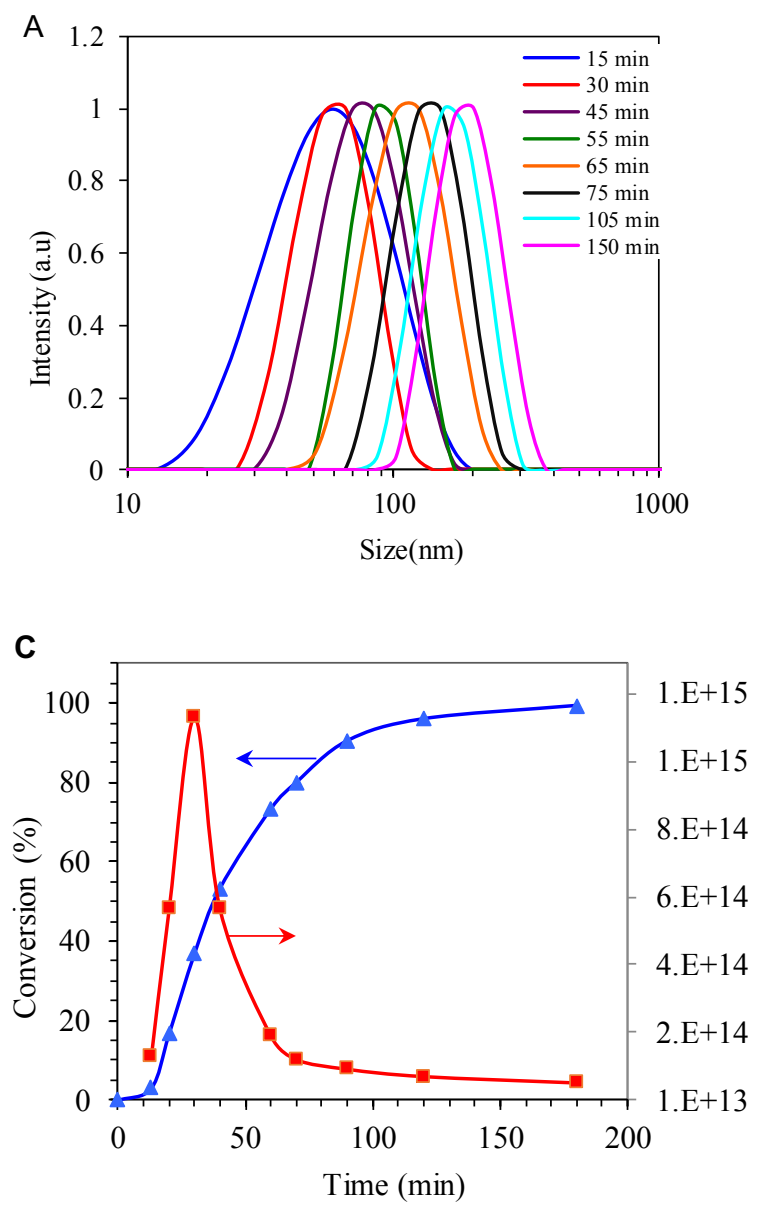

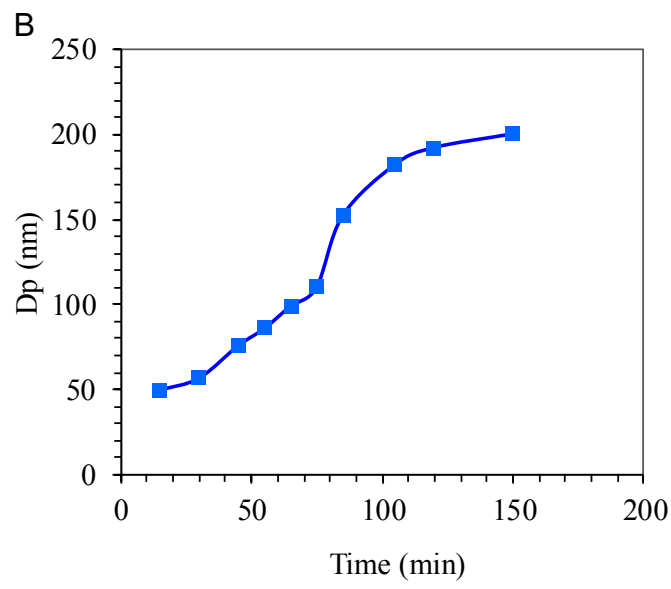

D

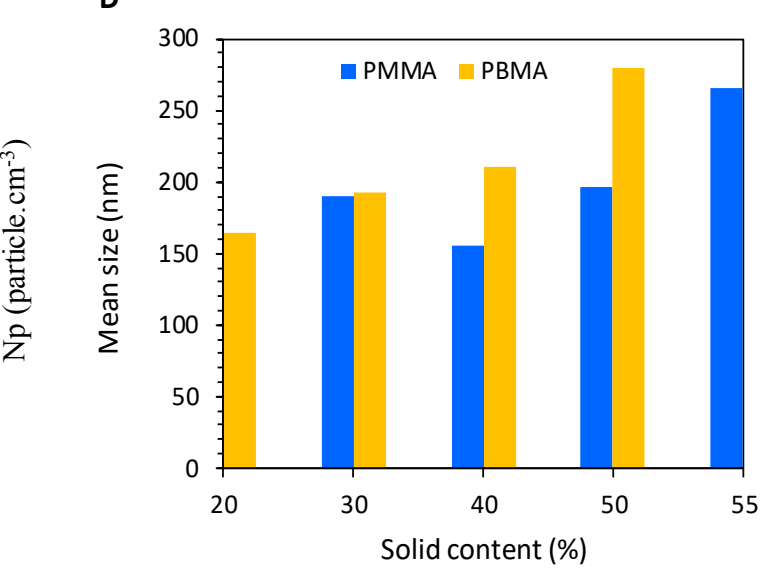

Figure 6. (A) Particle size distribution, (B) mean particle size, and (C) evolution of the number of polymer particles and conversion at different time interval during the emulsion polymerization of PBMA in the presence of $8 \mathrm{wt} \%$ dextrins at $50{ }^{\circ} \mathrm{C}$ using $\mathrm{H}_{2} \mathrm{O}_{2} / \mathrm{AA}$ initiator. (D) Mean particle size of the latex at different SCs for PBMA and PMMA ( $8 \mathrm{wt} \%$ dextrins, initiator: $\mathrm{H}_{2} \mathrm{O}_{2} / \mathrm{AA}$ ).

\subsection{Polymerization kinetics and effect of solid content}

The time evolution of the particle-size distribution, conversion, particle diameter (Dp), and the number of polymer particles for batch emulsion polymerization of BMA using $\mathrm{H}_{2} \mathrm{O}_{2} / \mathrm{AA}$ redox initiator are shown in Figure 6. The particle size distribution of polymer particles (Figure 6A,B) is shifted upward with time, indicating the progressive growth of the polymer particle during the polymerization reaction. The monomer consumption starts after an induction period of about 10 min (Figure 6C), over which the conversion rapidly increases up to about $50 \%$ after $50 \mathrm{~min}$ and then progressively decreases and level off after $120 \mathrm{~min}$, reaching a full conversion after $180 \mathrm{~min}$. The polymer particle size continually increased until conversion of about $95 \%$ reaching about $200 \mathrm{~nm}$ at the end of the polymerization. The particle number increased at the beginning of the polymerization, reaching a maximum of $1.210^{15}$ particles $\mathrm{cm}^{-3}$ after $30 \mathrm{~min}$ with about $20 \%$ conversion of monomer followed by a steep decrease to stabilize at about $510^{13}$ particles $\mathrm{cm}^{-3}$ 
after $90 \mathrm{~min}$. This evolution indicates the occurrence of particles coagulation after the first interval corresponding to the nucleation of polymer particles, after which the polymer particles continue to grow without notable aggregation until the depletion of monomer. This aggregation allows the polymer particles to gain further colloidal stability by increasing their coverage degree with grafted/coated dextrins. Indeed, if we consider that the grafting of dextrins took place immediately after the addition of the initiator giving rise to the nucleated polymer particles, and that the stabilization process mainly originates from the grafted dextrins acting as a steric barrier, then the aggregation of polymer particles observed at low conversion seemed necessary to increase their coverage degree with a grafted layer of dextrins and generate enough steric barrier for the stabilization of the polymer particles during their growth.

The effect of the latex SC was tested for MMA and BMA at $8 \mathrm{wt} \%$ dextrin content and using $\mathrm{H}_{2} \mathrm{O}_{2} / \mathrm{AA}$ initiator (Figure 6D). A stable latex dispersion was obtained up to 50 and $55 \mathrm{wt} \%$ SC for PBMA and PMMA, respectively, with particle size remaining in the range 150-250 nm. No obvious trend regarding the evolution of particle size with the SC, but over a SC of $50 \mathrm{wt} \%$ an increase in the mean particle size was observed for both PMMA and PBMA latexes. Over $50 \mathrm{wt} \%$, the aggregation of polymer particles with a formation of coarse lumps was observed during the polymerization run, indicating that the dispersion was no longer stable. For the different SCs tested, the latex dispersions remained stable over more than 3 months at $25^{\circ} \mathrm{C}$.
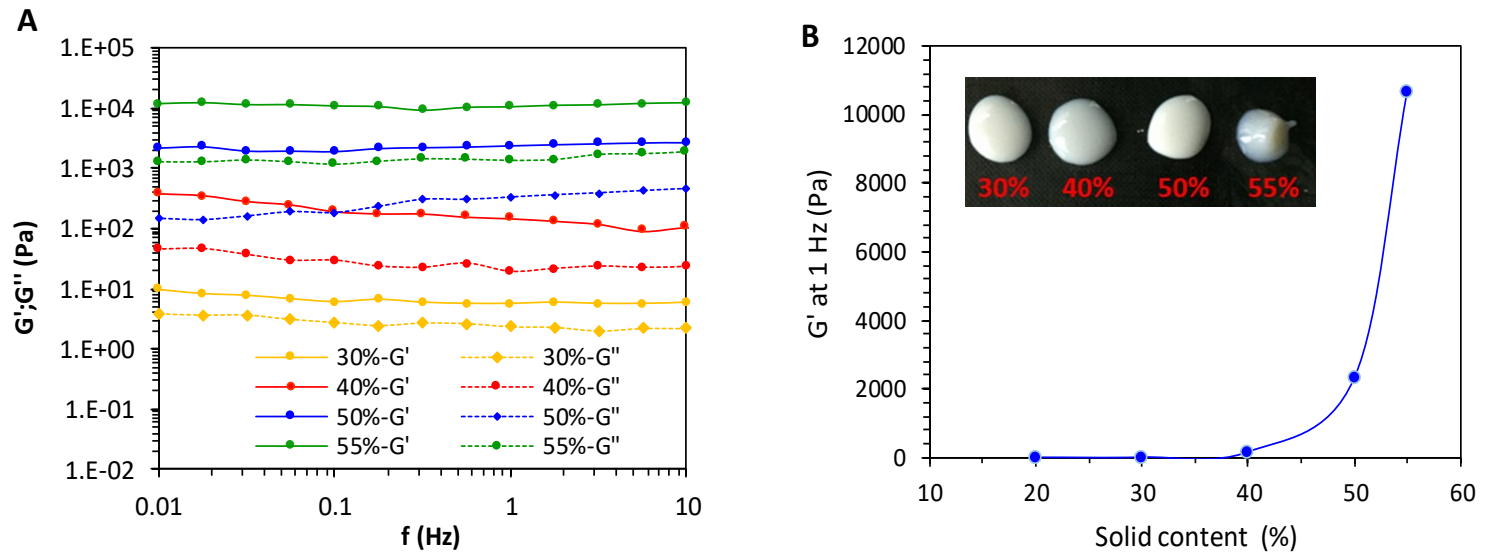

Figure 7. (A) Dynamic shear moduli $G^{\prime}$ and $G^{\prime \prime}$ at $25^{\circ} \mathrm{C}$, and (C) $G^{\prime}$ at $1 \mathrm{~Hz} v s$ solid content, for PMMA latex prepared using the $\mathrm{H}_{2} \mathrm{O}_{2} / \mathrm{AA}$ initiator at $50{ }^{\circ} \mathrm{C}$.

\subsection{Rheology of the dispersions}

The rheology of the latex prepared in the presence of dextrins at different SCs was studied for PMMA in the linear domain and under dynamic conditions to better highlight the evolution in the microstructural properties of the polymer dispersion with increasing SC. The storage 
modulus $\left(G^{\prime}\right)$ and loss modulus $\left(G^{\prime \prime}\right)$ as a function of frequency (f) in the linear regime is shown in (Figure 7A). For all PMMA latexes, $G^{\prime}$ and $G^{\prime \prime}$ were nearly frequency-independent, with $G^{\prime}$ being higher than $G^{\prime \prime}$ at $\mathrm{SC}>30 \mathrm{wt} \%$, and $G^{\prime} \approx G^{\prime \prime}$ at $30 \mathrm{wt} \% \mathrm{SC}$. This means that over $30 \mathrm{wt} \%$ $\mathrm{SC}$, the latex had a gel-like aspect which indicated the presence of a network structure resulting from the interaction of polymer particles. This weak interaction might result from the presence of the dextrin layer around the polymer particles that favors the possibility of interaction through hydrogen bonding between neighboring particles. $G^{\prime}$ increased with SC, indicating a strengthening in the gel-like character of the dispersion which is likely due to the increase in the number of polymer particles reducing the distance between neighboring particles, favoring interaction. The plot $G^{\prime} v s$ SC (Figure 7B) presents a typical evolution of concentrated dispersion where a sharp increase in $G^{\prime}$ is observed over $50 \%$ as the upper volume fraction limit of the dispersion is reached.

\subsection{Pressure-sensitive adhesive application}

In addition to its stabilizing action during the emulsion polymerization, the presence of dextrins coating the polymer particles might be further exploited to induce physical or chemical crosslinking of the polymer film, taking advantage of the reactivity of dextrins. An example of the additional functionality brought by the presence of dextrins encapsulating the latex particles is in acrylic waterborne pressure-sensitive adhesive (PSA) adhesive. The PSA adhesive was synthesized by the emulsion polymerization BA in the presence of $8 \mathrm{wt} \%$ dextrins at $40 \mathrm{wt} \% \mathrm{SC}$. For comparison purpose, a latex with the same monomer composition was prepared using ionic Doss surfactant as a stabilizer.

The viscoelastic property of the PSA film was analyzed by oscillatory frequency sweep measurements of the storage modulus $G^{\prime}$ and loss modulus $G^{\prime \prime}$ as a function of strain amplitude $(\gamma)$ or frequency (f) (Figure 8A,B). The PSA film was obtained by simply drying a sample of the PBA dispersion at $40{ }^{\circ} \mathrm{C}$ on a Teflon mold until complete evaporation of water. In this analysis, $G^{\prime}$ represents the elastic deformation of the material and is a measure of the stiffness degree at a given temperature and frequency, while $G^{\prime \prime}$ is indicative of dissipation and flow aptitude of the material. 

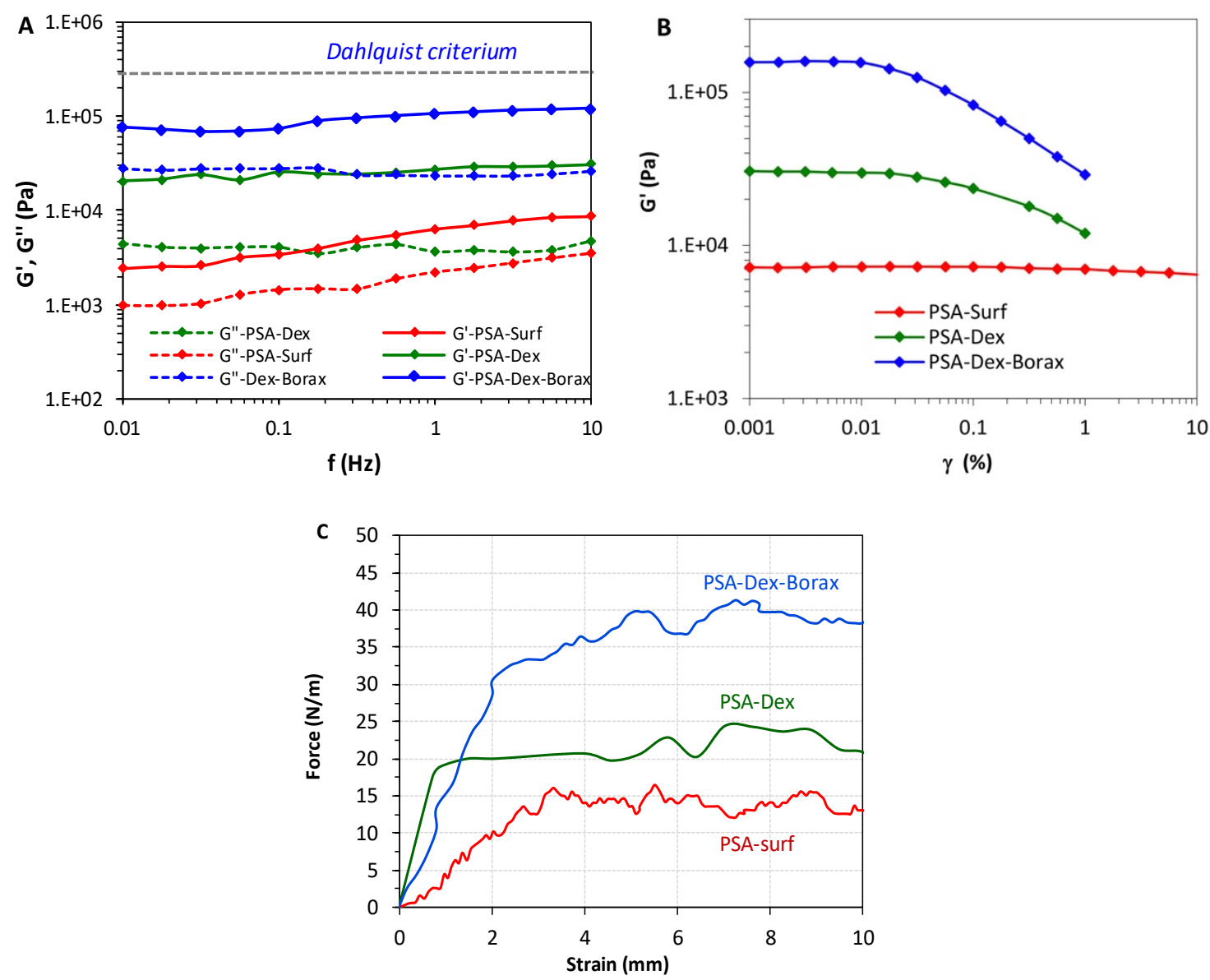

Figure 8. (A) $G^{\prime}$ and $G^{\prime \prime} v s$ frequency; (B) $G^{\prime}$ vs deformation at a frequency $1 \mathrm{~Hz}$, and (C) peeladhesion plot for PSA films (PSA-Surf: PBA dispersion prepared in the presence of surfactant; PSA-Dex: PBA prepared in the presence of dextrins, and PSA-Dex-Borax: PBA latex to which $0.5 \%$ borax was added).

For the different PSA compositions, $G^{\prime}$ at $0.01 \mathrm{~Hz}$ was below the Dahlquist criterium line $\left(G^{\prime}=3.310^{5} \mathrm{~Pa}\right.$ ), attesting of the tacky character of the films (Figure 8B) [30]. In addition, for all of them, $G^{\prime}$ was higher than $G^{\prime \prime}$ over the whole frequency domain, meaning that the elastic properties are dominant over the viscous flow. However, it can be seen that the presence of dextrins in the PSA latex led to an increase in the magnitude of $G^{\prime}$ in comparison of the neat PBA film, indicating an enhancement in the elastic character of the film. This effect may be due to a stiffening effect imparted by the presence of dextrins chemically linked to the PBA. The higher rigidity of the dextrin polymer in comparison of PBA would inevitably result in the enhancement in the elasticity of PBA-Dex polymer, even though dextrins were encapsulating the polymer particles. Interestingly, it can be seen that with the addition of a small amount of borax ( $0.5 \mathrm{wt} \%)$, a significant upward shift of of both $G^{\prime}$ and $G^{\prime \prime}$ of the PSA film could be seen (Figure 8B), which, referring to Chu's criteria, indicates an increase in the cohesive strength of the PSA [31]. 


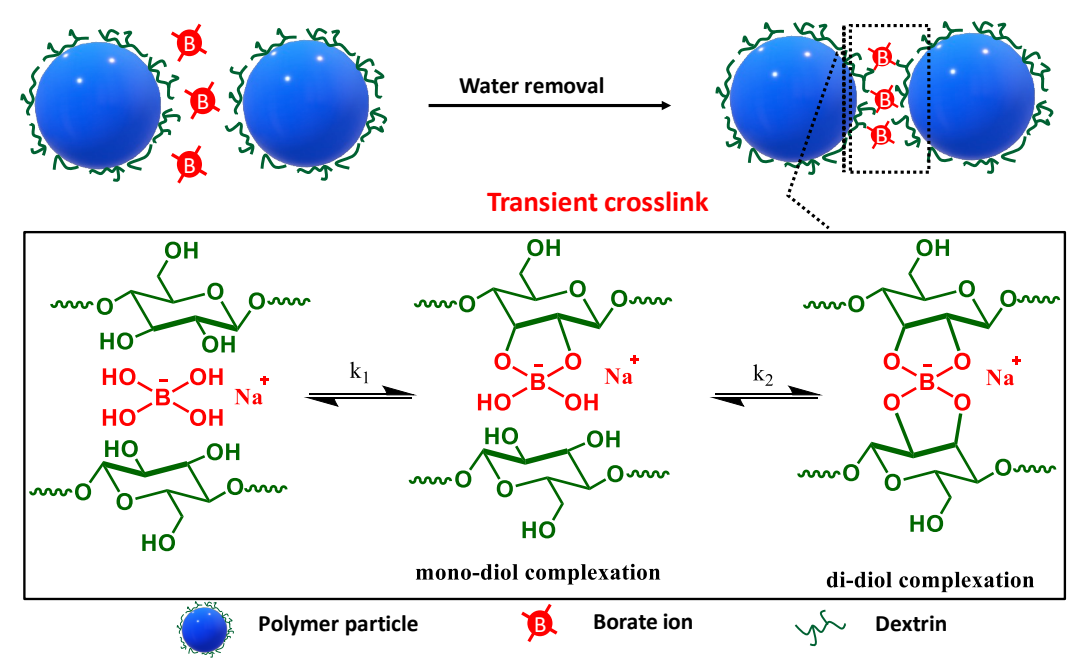

Scheme 3. Illustration of crosslinking effect induced by the addition of borax to the PBA-Dex PSA latex.

The increase in the cohesion of the PSA film after the addition of a small amount of borax to the PSA latex is explained to the generation of crosslinks between dextrin chains encapsulating the polymer particle, the magnitude of which becoming more prominent as water is removed and polymer particles get close to each other and coalesce. The sensitivity of poly(hydroxyl) compounds and polysaccharides to borax that induces partial crosslinking and gelling depending on the amount of added borax is well known. The gelation results from the formation of both covalent and hydrogen bonds involving a didiol complex [32] between borate and the two pairs of adjacent hydroxyl groups in two different chains, as illustrated in Scheme 3. When the rheology of the PSA film was analyzed in strain amplitude sweep, a rapid fall in $G^{\prime}$ was observed over a critical strain $\gamma_{c}$ of about $0.02 \%$ in PEHA-Dex and PEHA-DexBorax, with a marked effect for the latter, while $G^{\prime}$ was kept nearly constant up to a $10 \%$ deformation. This abrupt decrease in $G^{\prime}$ is indicative of a structural breakdown of a physical network when the film is slightly deformed. This means that the enhancement in the stiffness observed for the PSA latex prepared in the presence of dextrins or when borax was added to the as-prepared latex, resulted from the generation of a physical network that breaks down upon deformation. When borax was added to the PSA latex, the polymer particles came into contact once most of the water was removed, and the borax interacted with dextrins located on the surface of neighboring latex particles, creating a network formed by the crosslinking dextrin chains. Since the crosslinking of dextrins by borate results from an equilibrium diol complexation, the network could reversibly break and reform which explains the decrease of $G^{\prime}$ upon deformation, regaining its original value once the deformation was stopped. The generation of this network along with the extreme sensitivity of this network to deformation 
explains the huge increase in the the peel strength of the PSA coated on PP films (Figure 8C). As shown in Figure 8C, compared to the PSA latex produced by emulsion polymerization of EHA in the presence of an anionic surfactant, an enhancement by about $40 \%$ of the peel strength was noted for the PSA latex prepared in the presence of dextrins (PSA-Dex). The peel strength was even substantially enhanced by more than $100 \%$ in the presence of small amount of borax (about $0.5 \mathrm{wt} \%$ ). Based on the rheological data, the main reason for this enhancement in the peel strength could be attributed to the generation of the network induced by the addition of borax that enhanced the cohesion of the PSA film. The sensitivity to deformation of the network generated in the presence of borax might explain the maintenance of the wetting property of the PSA. Under the effect of applied pressure, the magnitude of $G^{\prime \prime}$ decreased allowing the substrate to be wetted by the adhesive.

\section{Conclusion}

In the present work, dextrin-coated polymer latexes prepared by emulsion polymerization of acrylic or vinylic monomers using a water-soluble initiator without the addition of either surfactant or costabilizer monomer was reported. Stable latex dispersions with SCs up to $55 \mathrm{wt} \%$ and dextrins from 2 to $12 \mathrm{wt} \%$ (based on monomer) were produced during a 3-4-h polymerization when the KPS or $\mathrm{H}_{2} \mathrm{O}_{2} /$ AA redox initiator was used. The particle size strongly depended on the amount of added dextrins, confirming the key role of the latter on in the stabilization process. Despite the lack of surface activity, the effective stabilizing action of dextrins in emulsion polymerization was explained by the coating of the polymer particle by dextrins during the growth process through $\mathrm{H}$-abstraction and monomer addition. This process was affected by the structure of the initiator, which justifies the strong dependence of the particle size and polymerization kinetics on the type of initiator. The most effective one was the $\mathrm{H}_{2} \mathrm{O}_{2}$ /AA redox initiator. Beyond its stabilization effect, the presence of dextrins coating the polymer particles might further be exploited to induce physical or chemical crosslinking of the polymer film, taking advantage of the dextrin reactivity. This was demonstrated in a PBA latex synthesized in the presence of $8 \mathrm{wt} \%$ dextrins, which was tested as waterborne PSA acrylic adhesive. It was shown that the addition of only $0.5 \mathrm{wt} \%$ of borax to the latex strongly enhanced the peel strength of the PSA adhesive without compromising the stability of the latex dispersion. This increase in the cohesion and adhesive property contributed to the use of the latex as acrylic PSA adhesive without the need for the addition of a tackifier to improve the cohesion of the adhesive tape. 


\section{Acknowledgements}

The authors acknowledge LabEx Tec 21-France (Investissements d'Avenir \#ANR-11LABX-0030), as well as the PHC Utique 19G1123 and Glyco@Alps programs (Investissements d'Avenir \#ANR-15-IDEX-02) for financial support. We thank the NanoBioICMG Platform (UAR 2607, Grenoble) for granting access to the Electron Microscopy and NMR facility. CERMAV and LRP are part of Institut Carnot PolyNat-France (Investissements d'Avenir \#ANR-11-CARN-030-01). We thank Christine Lancelon-Pin (CERMAV) for the SEM observations, as well as Stéphanie Pradeau and Patricia Chaud (CERMAV) for the NMR experiments.

\section{Supporting Information}

\section{Emulsion polymerization protocol:}

An example of latex formulation with $30 \mathrm{wt} \%$ solid content in the presence of $8 \mathrm{wt} \%$ dextrins as stabilizer is given in Table S1. The polymerization was performed as follows: water, dextrin solution (10 wt $\%$ in water), AA, and the monomer were mixed and kept under magnetic stirring. After flushing with $\mathrm{N}_{2}$, the mixture was placed in a heated bath at $50{ }^{\circ} \mathrm{C}$ and the polymerization was triggered by the addition of $\mathrm{H}_{2} \mathrm{O}_{2}$ for $1.5 \mathrm{~h}$. The polymerization was pursued for $2 \mathrm{~h}$ to ensure complete consumption of the monomer. Once the latex reached the theoretical solid content (here $30 \mathrm{wt} \%$ ), the latex was recovered and $0.1 \mathrm{~g}$ of $0.1 \% \mathrm{NaN}_{3}$ was added to prevent bacterial growth.

Table S1. Emulsion polymerization of BMA in the presence of dextrins as sole stabilizer, carried out at $50{ }^{\circ} \mathrm{C}$.

\begin{tabular}{cc}
\hline Constituent & Composition $(\mathrm{g})$ \\
\hline Water & 14.5 \\
Dextrins (10 wt\% solution) & 2.4 \\
$\mathrm{BMA}$ & 3.0 \\
$\mathrm{H}_{2} \mathrm{O}_{2}(30 \%)$ & 0.15 \\
$\mathrm{AA}$ & 0.06 \\
\hline
\end{tabular}




\section{References}

[1] C. S. Chern, Emulsion polymerization mechanisms and kinetics, Prog. Polym. Sci. 31 (2006) 443-486.

[2] S. Paul, Water-borne acrylic emulsion paints, Prog. Org. Coatings. 5 (1977) 79-96.

[3] M. J. Scott, M. N. Jones, The biodegradation of surfactants in the environment, Biochim. Biophys. Acta Biomembr. 1508 (2000) 235-251.

[4] M. Egen, R. Zentel, Surfactant-free emulsion polymerization of various methacrylates: Towards monodisperse colloids for polymer opals, Macromol. Chem. Phys. 205 (2004) 1479-1488.

[5] P. A. Lovell, F. J. Schork, Fundamentals of emulsion polymerization, Biomacromolecules 21 (2020) 4396-4441.

[6] A. Guyot, K. Tauer, Reactive surfactants in emulsion polymerization, Adv. Polym. Sci. 111 (1994) 42-65.

[7] H. Dupont, V. Maingret, V. Schmitt, V. Héroguez, New insights into the formulation and polymerization of Pickering emulsions stabilized by natural organic particles, Macromolecules 54 (2021) 4945-4970.

[8] E. Dickinson, Hydrocolloids as emulsifiers and emulsion stabilizers, Food Hydrocoll. 23 (2009) 1473-1482.

[9] M. Benna-Zayani, N. Kbir-Ariguib, M. Trabelsi-Ayadi, J.L. Grossiord, Stabilisation of W/O/W double emulsion by polysaccharides as weak gels, Colloids Surf. A 316 (2008) $46-54$.

[10] A. Paraskevopoulou, D. Boskou, V. Kiosseoglou, Stabilization of olive oil - Lemon juice emulsion with polysaccharides, Food Chem. 90 (2005) 627-634.

[11] E. Dickinson, Hydrocolloids at interfaces and the influence on the properties of dispersed systems, Food Hydrocoll. 17 (2003) 25-39.

[12] N. M. B. Smeets, S. Imbrogno, S. Bloembergen, Carbohydrate functionalized hybrid latex particles, Carbohydr. Polym. 173 (2017) 233-252.

[13] S. C. Abeylath, E. Turos, S. Dickey, D. V. Lim, Glyconanobiotics: Novel carbohydrated nanoparticle antibiotics for MRSA and Bacillus anthracis, Bioorganic Med. Chem. 16 (2008) 2412-2418.

[14] C. Chauvierre, D. Labarre, P. Couvreur, C. Vauthier, Novel polysaccharide-decorated poly(isobutyl cyanoacrylate) nanoparticles, Pharm. Res. 20 (2003) 1786-1793.

[15] S. Cheng, W. Zhao, Y. Wu, Optimization of synthesis and characterization of oxidized starch-graft-poly(styrene-butyl acrylate) latex for paper coating, Starch/Staerke 67 (2015) 493-501.

[16] A. S. Kedzior, V. A. Gabriel, M. A. Dubé, E. D. Cranston, Nanocellulose in emulsions and heterogeneous water-based polymer systems: A review, Adv. Mater. 2020, 2002404

[17] S. B. Haaj, W. Thielemans, A. Magnin, S. Boufi. Starch nanocrystal stabilized Pickering emulsion polymerization for nanocomposites with improved performance, ACS Appl. Mater. Inter. 6 (2014) 8263-8273.

[18] F. Ben Cheikh, A. Ben Mabrouk, A. Magnin, J.-L. Putaux, S. Boufi, Chitin nanocrystals as Pickering stabilizer for $\mathrm{O} / \mathrm{W}$ emulsions: Effect of the oil chemical structure on the emulsion properties. Colloid. Surf. B 200 (2021), 111604. 
[19] H. De Bruyn, E. Sprong, M. Gaborieau, J. A. Roper, R. G. Gilbert, Starch-graft(synthetic copolymer) latexes initiated with $\mathrm{Ce}^{4+}$ and stabilized by amylopectin, J. Polym. Sci. Part A Polym. Chem. 45 (2007) 4185-4192.

[20] H. De Bruyn, E. Sprong, M. Gaborieau, G. David, J.A. Roper, R.G. Gilbert, Starchgraft-copolymer latexes initiated and stabilized by ozonolyzed amylopectin, J. Polym. Sci. Part A Polym. Chem. 44 (2006) 5832-5845.

[21] S. Cheng, Y. Zhao, Y. Wu, Surfactant-free hybrid latexes from enzymatically hydrolyzed starch and poly(butyl acrylate-methyl methacrylate) for paper coating, Prog. Org. Coatings 118 (2018) 40-47.

[22] S. Cheng, Y. Zhao, Synthesis of eccentric core-shell particles by surfactant-free emulsion polymerization with enzymatically hydrolyzed starch as the stabilizer, Colloid Polym. Sci. 295 (2017) 2233-2241.

[23] S. Cheng, Y. Zhao, Y. Wu, Surfactant-free hybrid latexes from enzymatically hydrolyzed starch and poly(butyl acrylate-methyl met hacrylate) for paper coating, Prog. Org. Coatings 118 (2018) 40-47

[24] S. Cheng, Y. Zhao, Synthesis of eccentric core-shell particles by surfactant-free emulsion polymerization with enzymatically hydrolyzed starch as the stabilizer, Colloid Polym. Sci. 295 (2017) 2233-2241

[25] J. N. BeMiller, Dextrins, In "Encyclopedia of Food Sciences and Nutrition", Second Edition, 2003.

[26] R. Ferrari, G. Storti, M. Morbidelli, Maltodextrin as stabilizer for emulsion polymerization: Adsorption and grafting behavior, J. Polym. Sci. 58 (2020) 1642-1654.

[27] G. Moad, Chemical modification of starch by reactive extrusion, Prog. Polym. Sci. 36 (2011) 218-237.

[28] G. Odian, Principles of Polymerization, $3^{\text {rd }}$ edn. Wiley, New York, 1991.

[29] I. W. Noordergraaf, T. K. Fourie, P. Raffa, Free-radical graft polymerization onto starch as a tool to tune properties in relation to potential applications. A review, Processes 6 (2018) 31 .

[30] C. A Dahlquist, Pressure Sensitive Adhesives, in "Treatise on adhesion and adhesives", edited by R. L. Patrick, Marcel Dekker, New York, 1969, Vol. 2.

[31] J. B. Class, S. G. Chu, The viscoelastic properties of rubber-resin blends. II. The effect of resin molecular weight, J. Appl. Polym. Sci. 30 (1985) 815-824.

[32] E. Pezron, L. Leibler, A. Ricard, R. Audebert, Reversible gel formation induced by ion complexation. 2. Phase diagrams, Macromolecules 21 (1988) 1126-1131. 